\title{
Gastrointestinal Stromal Tumors: Correlation of Multislice CT Findings to Histopathologic Features and Preliminary Validation of New Scoring System
}

\author{
Leila Mchirgui ${ }^{1}$, Rabii Noomene ${ }^{2 *}$, Chiraz Jemli Chammakhi' ${ }^{1}$, Mohammed Habib Daghfous ${ }^{1}$ \\ ${ }^{1}$ Department of Radiology, Habib Thameur Hospital, Tunis, Tunisia \\ ${ }^{2}$ Department of General Surgery, Habib Thameur Hospital, Tunis, Tunisia \\ Email: *rabiinoomene@yahoo.fr
}

Received 1 January 2016; accepted 19 March 2016; published 23 March 2016

Copyright (C) 2016 by authors and Scientific Research Publishing Inc.

This work is licensed under the Creative Commons Attribution International License (CC BY). http://creativecommons.org/licenses/by/4.0/

cC) (i) Open Access

\section{Abstract}

Purpose: The purpose of this study is to demonstrate the correlation between radiologic and pathologic features of the gastrointestinal stromal tumors. Patients and methods: A retrospective review from 2004 to 2014 identified 50 resected cases of confirmed gastrointestinal stromal tumors (GIST) is done. All these lesions were visualized in the first multi-slice computed tomography (MSCT) investigation. Radiologic and pathologic features were reviewed and compared. A radiologic score with MSCT findings was established. Four levels of risk were defined and compared to the Miettinen-Lasota prognostic classification. Results: Mean patients' age was $\mathbf{5 7 . 6}$ with a sexratio (M/F) of 1.17. Of the 50 GISTs lesions, 29 were located in the stomach (58\%), 3 in the duodenum (6\%), 16 in the small intestine (32\%), one in the rectum and one in the great omentum. MSCT images were evaluated for origin and size of the tumor, as well as growth pattern, density before and after contrast, relationship with adjacent structures, presence of lymph nodes, ascitis and metastasis. The presence of mucosal ulceration, calcification, necrosis, cystic area or hemorrhage into the lesion was emphasized for each case. The histologic equivalent criteria were gathered from histopathology examination review of all specimens. Significant correlation was found for all these findings except the hemorrhage $(p=0.071)$. A radiologic score of fifteen items variable between 0 and 18 was established. Miettinen risk classification was noted for each lesion. GISTs with very low risk had MSCT score < 4. GIST with low risk had a MSCT score between 5 and 9. GIST with moderate risk had a score between 10 and 14 and those with high risk had an MSCT score between 15 and 18. Significant correlation was found between the radiologic and histopathologic risk classification $(p=0.001)$. Conclusion: MSCT is helpful in risk prediction for GIST.

\footnotetext{
${ }^{*}$ Corresponding author.
}

How to cite this paper: Mchirgui, L., Noomene, R., Chammakhi, C.J. and Daghfous, M.H. (2016) Gastrointestinal Stromal Tumors: Correlation of Multislice CT Findings to Histopathologic Features and Preliminary Validation of New Scoring System. Open Journal of Radiology, 6, 29-38. http://dx.doi.org/10.4236/ojrad.2016.61005 


\section{Keywords}

\section{Gastrointestinal Stromal Tumors, Multi-Slice Computed Tomography, Pathology, Prognosis}

\section{Introduction}

Gastrointestinal stromal tumors (GISTs) are the most common primary mesenchymal neoplsms of the digestive tract. They derive from a precursor of the interstitial cells of Cajal, normally present in the myenteric plexus. All digestive segments can be affected but these tumors most commonly occur in the stomach (70\%). Specific mutations in the Kit gene are present in $86 \%$ of cases and in platelet-derived growth factor receptor (PDGFR) gene in $15 \%$ of cases. The marker CD 117 is present in 95\% of cases. The management of GIST is based on surgery. Only localized tumors eligible for Ro resection are associated with long survival. The radiologic and pathologic characterization of this entity was permitted to codify the surgical management and improved the prognosis. The tyrosinekinase inhibitors (TKI) are standard in first-line metastatic and locally advanced GISTs treatment. All risk stratification systems proposed for GISTs depend on histologic factors. The aim of our study was to demonstrate the role of the multi-slice computed tomography (MSCT) in the prognosis assessment in order to validate the first radiologic scoring system.

\section{Materials and Method}

We retrospectively reviewed the MSCT and specimen microscopic examination findings of 50 patients with confirmed GIST in the period between 2004 and 2014. All patients underwent surgical resection and diagnosis confirmation was provided by pathology examination. Four cases of patients for whom MSCT was unavailable were excluded. The evaluation of all MSCT features was performed by the same radiologist. Scans were reviewed to determine the size, contour, boundary, growth pattern, degree of enhancement, and tumors necrosis. The presence of calcification, ulceration, cystic area, and hemorrhage within the lesions as well as fat infiltration, lymph nodes, ascitis, and metastasis was also recorded. The histological review of specimens was performed by the same pathologist blindly to radiologic results. Macroscopic description was obtained from existing patients reports. The microscopic examination was redone for all cases. The prognostic classification was updated to Miettenen-Lasota grading system for 6 patients. Statistical analysis of the gathered information was performed using SPSS20.0 software. A comparative study of radiologic and pathologic criteria was performed by quisquare and exact test. The significance was retained for $\mathrm{P}$ value $<0.05$. The prognostic impact of radiologic criterions was assessed by the Kaplan Meyer method. MSCT correlating findings were gathered in a scoring system of fifteen items. The preliminary validation of the MSCT score in the prediction of risk was obtained using the receiver operating characteristic curve (ROC). Using this new tool, four level of risk were defined. The new stratification was compared with the Miettineen-Lasota classification $(\mathrm{P}<0.05)$. This study was approved by the research ethics committee of the hospital.

\section{Results}

Patient's descriptive analysis is shown in Table 1.

Socio-demographic data showed that of the 50 patients there were 27 males and 23 females (sex-ratio of 1.17). Mean patients age was 57.6 (15 - 72). GIST was located in the stomach in 29 cases (58\%), in the duodenum in 3 cases (6\%), in the small intestine in 16 cases (32\%). One GIST was located in the rectum and another one in the great omentum. Symptoms were variable. Bleeding was seen in $64.2 \%$ of cases, abdominal pain in $58.4 \%$, changed bowel habits in $22 \%$ and weight loss in $14 \%$. The lesion was discovered incidentally in two patients during a periodic medical check-up. All patients underwent surgical treatment. For gastric GISTs, total gastrectomy was performed in 8 cases between 2004 and 2008 mostly because of the doubt about the tumor nature. Otherwise surgery consisted in complete tumor resection with macroscopic negative margin over the stomach. In case of small bowel GISTs, resection and anastomosis were performed for all patients. Omentectomy was performed for the omental GIST and proctectomy for the rectal localization. Surgery was performed in an emergency in 4 cases because of a massive gastrointestinal bleeding. Morbidity was about $4.8 \%$ and mortality 
Table 1. Descriptive analysis.

\begin{tabular}{|c|c|}
\hline Characteristics & $n$ \\
\hline \multicolumn{2}{|l|}{ Age } \\
\hline - Mean & 57.6 \\
\hline - Range & $15-72$ \\
\hline \multicolumn{2}{|l|}{ Sex } \\
\hline - Male & 27 \\
\hline - Female & 23 \\
\hline \multicolumn{2}{|l|}{ Presenting symptoms } \\
\hline • Gastrointestinal bleeding & 32 \\
\hline - Abdominal pain & 29 \\
\hline & 11 \\
\hline - Change in bowel habit & 7 \\
\hline $\begin{array}{l}\text { - Weight loss } \\
\text { - Asymptomatic }\end{array}$ & 2 \\
\hline \multicolumn{2}{|l|}{ Lesion location } \\
\hline$\bullet$ Stomach & 29 \\
\hline - Duodenum & 3 \\
\hline • Jejunum & 4 \\
\hline • Ileum & 12 \\
\hline - Rectum & 1 \\
\hline - Omentum & 1 \\
\hline
\end{tabular}

about $8 \%$ essentially related to metastasis progression. Local recurrence occurred in 6 patients (12\%) Overall survival was $58.5 \%$ and recurrence free survival was $64 \%$.

\subsection{MSCT Findings}

MSCT tumors description is detailed in Table 2.

Mean tumors size was 11.6 centimeters (3 - 25). Heterogeneous multi-lobulated mass is the most frequently observed aspect (80\%). Intravenous contrast was used for all the patients. Oral contrast was used in $70 \%$ of cases. Multiplanar reconstruction was performed in all cases .the enhancement degree was variable. It was moderate and heterogeneous in $60 \%$ of cases. Tumor necrosis was observed in varying proportions as spontaneously hypodense areas not enhanced after contrast injection (76\%). Cystic tumoral area was observed in 9 gastric GISTs. Calcifications and tumoral hemorrhage were rare. Mucosal ulceration was seen in 3 cases of duodenal GISTs. In the case of omental GIST, MSCT localization was difficult to perform due to the big size of the tumor (Figure 1(a) and Figure 1(b)).

\subsection{Pathology Findings}

The review of all macroscopic specimen examinations as well as the microscopic study was done by the same pathologist blindly to MSCT informations. Only intraoperative findings were accessible in the patient's records during the histologic review. For 6 patients, GISTs was classified according Fletcher grading system. The study permitted an update of the classification. Most of the tumors presented as a rounded or lobulated mass with well circumscribed boundary (60\%). Mean tumors size was $10.92 \mathrm{~cm}(4-25)$. Small lesions had ahomogeneous aspect overall section surface, while the large lesions $(>10 \mathrm{~cm})$ presented frequent zones with necrosis $(72 \%)$, hemorrhage (28\%) and cystic degeneration (26\%). Moderate to high cellularity was seen in $58 \%$ of cases. Eighty five percent of tumors were predominantly of the spindle cell type. GISTs with epithelioid cells were found in particular ingastric localization (60\%). In four cases a mixed architecture was seen.

Approximately 90\% of GISTs displayed a positive staining for c-kit (CD117).The immune staining was variable for other markers such as CD34 (60\%), smooth muscle act in (50\%), neural protein S100 (8\%), and desmin (5\%). Dog 1 marker, recently introduced in our practice was not considered in this study. Final histopathology examination showed 12 GISTs with very low risk, 9 GISTs with low risk, 11 GISTs with moderate risk, and 18 with high risk. Inflammatory lymph nodes were found in 14 cases. In one case an objective lymph node metastasis was seen. The comparison between MSCT and pathology findings is shown in Table 3. 
Table 2. MSCT ${ }^{*}$ tumors description.

\begin{tabular}{|c|c|}
\hline Features & $n$ \\
\hline \multicolumn{2}{|l|}{ Size } \\
\hline Mean & 11.6 \\
\hline Range & $3-25$ \\
\hline \multicolumn{2}{|l|}{ Origin } \\
\hline Stomach & 29 \\
\hline Duodenum & 3 \\
\hline Jejunum & 6 \\
\hline Ileum & 10 \\
\hline Rectum & 1 \\
\hline Unknown & 1 \\
\hline \multicolumn{2}{|l|}{ Growth pattern } \\
\hline Endoluminal & 12 \\
\hline Exoluminal & 12 \\
\hline Mixed & 26 \\
\hline \multicolumn{2}{|l|}{ Enhancement } \\
\hline Poor & 8 \\
\hline Heterogeneous & 30 \\
\hline Massive & 12 \\
\hline \multicolumn{2}{|l|}{ Contour } \\
\hline Multi-lobulated & 40 \\
\hline Rounded & 10 \\
\hline \multicolumn{2}{|l|}{ Boundary } \\
\hline Clear & 38 \\
\hline Unclear & 12 \\
\hline Calcification & 4 \\
\hline Necrosis & 38 \\
\hline Hemorrhage & 2 \\
\hline Ulceration & 3 \\
\hline Fat infiltration & 5 \\
\hline Cystic area & 9 \\
\hline Invasion of adjacent organs & 5 \\
\hline Ascitis & 4 \\
\hline Metastasis & 4 \\
\hline Lymphadenopathy & 12 \\
\hline Carcinomatosis nodule & 2 \\
\hline
\end{tabular}

*MSCT: multislice computed tomography

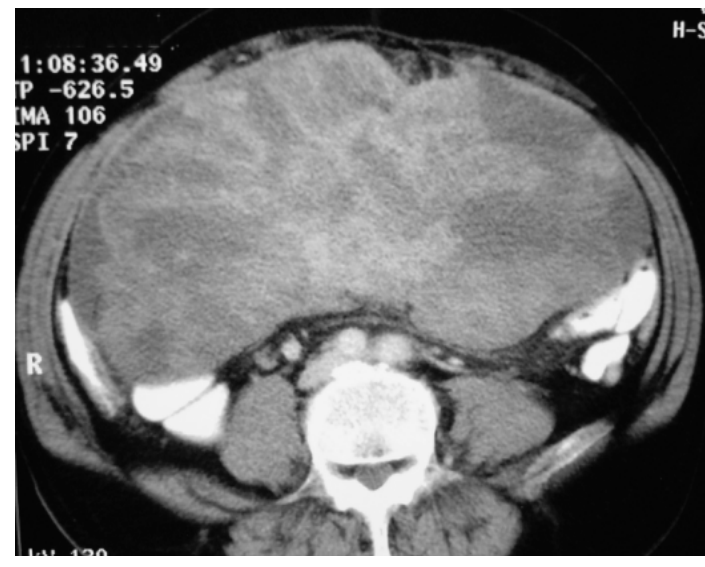

(a)

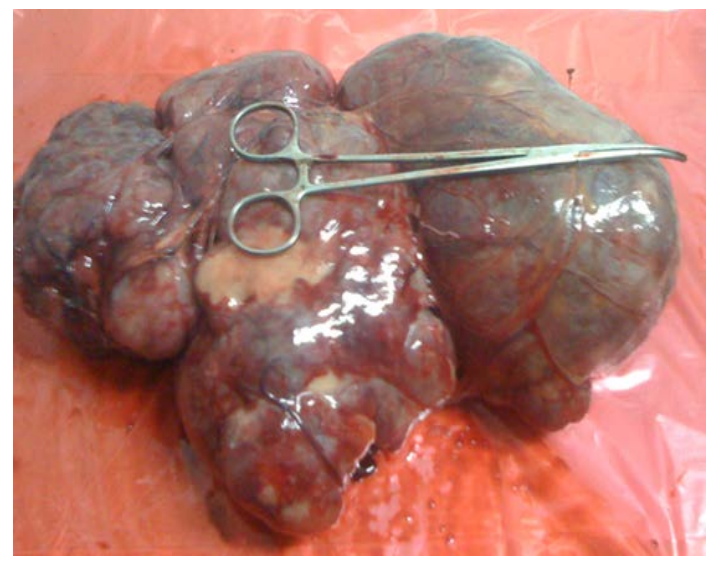

(b)

Figure 1. A 72-year-old male complaining from abdominal pain and weight loss. Examination showed a fixed abdominal mass; due its big size CT could not conclude about its origin (a), surgical removal specimen examination showed a $25 \mathrm{~cm}$ tumor of the omentum (b). 
Table 3. MSCT* vs. pathology findings.

\begin{tabular}{lcc}
\hline \multicolumn{1}{c}{ Criteria } & MSCT/Pathology & $\boldsymbol{p}$ \\
\hline Mean size & $11.6 / 10.92$ & \\
Multi-lobulated contour & $40 / 43$ & 0.012 \\
Mixed growth pattern & $26 / 32$ & 0.002 \\
Unclear boundary & $12 / 10$ & 0.022 \\
Calcification & $4 / 4$ & 0.001 \\
Necrosis & $38 / 43$ & 0.031 \\
Hemorrhage & $2 / 12$ & 0.71 \\
Ulceration & $3 / 4$ & 0.012 \\
Fat infiltration & $5 / 3$ & 0.042 \\
Cystic area & $9 / 12$ & 0.03 \\
Ascitis & $4 / 4$ & 0.001 \\
Liver metastasis & $4 / 4$ & 0.001 \\
Carcinomatosis nodule & $2 / 3$ & 0.001 \\
Lymphadenopathy & $12 / 14$ & 0.01 \\
\hline
\end{tabular}

*MSCT: multislice computed tomography

The evident correlation between MSCT and pathology tumors characteristics was helpful to elaborate an MSCT score for the evaluation of GISTs. It was mandatory to determine if MSCT findings were useful for the prognosis assessment. Kaplan Mayer approach was more adapted to the study due to the small size of the data. Overall survival and recurrence free survival were used as dependent. Log-rank test analysis showed that tumors sized above $5 \mathrm{~cm}(p=0.032)$, non-gastric localization ( $=0.012)$, multi-lobulated contour $(p=0.022)$, unclear boundary $(\mathrm{p}=0.01)$, mixed growth pattern $(\mathrm{p}=0.03)$, heterogeneous aspect and moderate enhancement $(\mathrm{p}=$ $0.038)$, necrosis $(p=0.014)$, mucosal ulceration $(p=0.032)$, cystic area $(p=0.012)$, ascitis $(p=0.023)$, metastasis $(p=0.012)$, fat infiltration $(p=0.023)$, carcinomatosis nodule $(p=0.001)$, multiples lymph nodes $(p=0.012)$ appeared as independent prognostic factors. The MSCT score could be elaborated. This score is detailed in Table 4 .

The score is variable between 0 and 18 . The receiver operating characteristic (ROC) curve was performed for a preliminary validation in a stepwise procedure (confidence interval CI $=95 \%)$. Maximum of specificity $(84 \%)$ and sensibility (78\%) were seen in cutoff value of 9 . Patients could be stratified by risk using these findings into 2 groups. Low risk GISTs if MSCT score $<9$ and high risk GIST if MSCT score $>9(\mathrm{p}=0.003)$ (Figure 2). It has been proposed to use a new model of 4 groups:

Very low risk group: MSCTI (score is 0 to 4), Low risk: MSCT II (score 5 to 9), Moderate risk: MSCT III (score 10 to 14), High risk: MSCT IV score (15 to 18).

The ROC curve model was reestablished for each subgroup. The area under the curve (AUC) was significant for all the subgroups of the MSCT score. AUC for the validation of MSCT I was 0.92 (95\% CI, 0.85 - 0.96), for MSCT II was 0.9 (95\% CI, 0.85 - 0.95), for MSCTIII was 0.86 (95\% CI, 0.85 - 0.96) and for MSCT IV was 0.78 (95\% CI, 0.75 - 0.85) (Figure 3).

The final step in the statistical analysis was to evaluate the clinical utility of the MSCT score in the assessment of GIST risk. A comparison between the Miettenen-Lasota and the new scoring system was performed using inter rater agreement between them as tow categorical items (Cohen's kappa coefficient). The correlation was significant $(\mathrm{Kappa}=0.82 \mathrm{p}=0.001)$. The results are shown in Table 5 .

\section{Discussion}

Appropriate management of GISTs requires accurate diagnosis and must always involve a multidisciplinary team (MDT) approach. Eighty five percent of primary GISTs are resectable and diagnosis is usually confirmed by the histopathologic examination of removed specimens [1] [2]. In these cases, initial diagnosis is based on imaging [3].The type of investigation used initially will depend on the mode of presentation and local availability. Because of the unavailability of the endoscopic ultrasound (EUS) and the FDG PET scan, MSCT is usually the initial investigation. GISTs characterization as a distinct entity permitted to codify some specific radiologic features [4] [5]. Our study showed that the MSCT is useful in the diagnosis of primary tumor, and guides decision in case of complication. 
GISTs prognosis can vary significantly among patients within the same stage. Response to treatment is usually unpredictable and recurrence can occur in 50\% of properly resected cases [6] [7]. Many validated prognosis stratification tools are available in the assessment of patient's outcome. The Armed Forces Institute of Pathology (AFIP) risk stratification, the modified National Institutes of Health (NIH) scheme, and the prognostic heat maps may be the most frequently used methods. All of these schemes consider tumor mitotic count, site and size. Tu-

Table 4. MSCT* score.

\begin{tabular}{lr}
\hline \multicolumn{1}{c}{ Criteria } & \multicolumn{1}{c}{ Score calculation } \\
\hline Size $(\mathrm{cm})$ & $<5=0.5$ to $10=1,>10=2$ \\
Localization & Gastric $=0$, other $=1$ unknown $=2$ \\
Contour & Rounded $=0$, lobulated $=1$ \\
Growth pattern & Endo or exoluminal $=0$, mixed $=1$ \\
Aspect before contrast & Homogenous $=0$, heterogeneous $=1$ \\
Enhancement & Massive $=0$, moderate $=1$ \\
Boundary & Clear $=0$, unclear $=1$ \\
Necrosis & Absent $=0$, moderate $=1$, severe $=2$ \\
Ulceration & Absent $=0$, Present $=1$ \\
Cystic area & Absent $=0$, Present $=1$ \\
Ascitis & Absent $=0$, Present $=1$ \\
Fat infiltration & Absent $=0$, Present $=1$ \\
Liver metastasis & Absent $=0$, Present $=1$ \\
Carcinomatosis nodule & Absent $=0$, Present $=1$ \\
Lymphadenopathy & Absent $=0$, Present $=1$ \\
\hline
\end{tabular}

${ }^{*}$ MSCT: multislice computed tomography

\section{ROC curve}

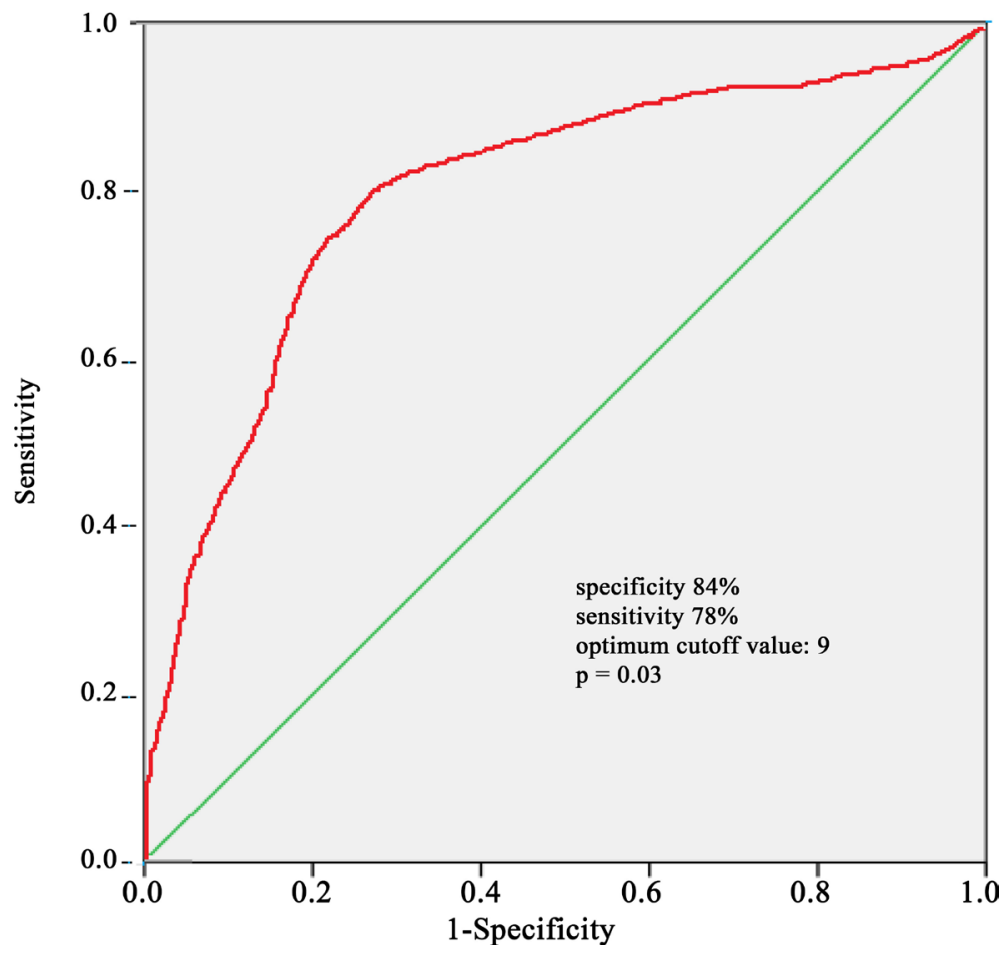

Figure 2. ROC curve analysis for MSCT score. 

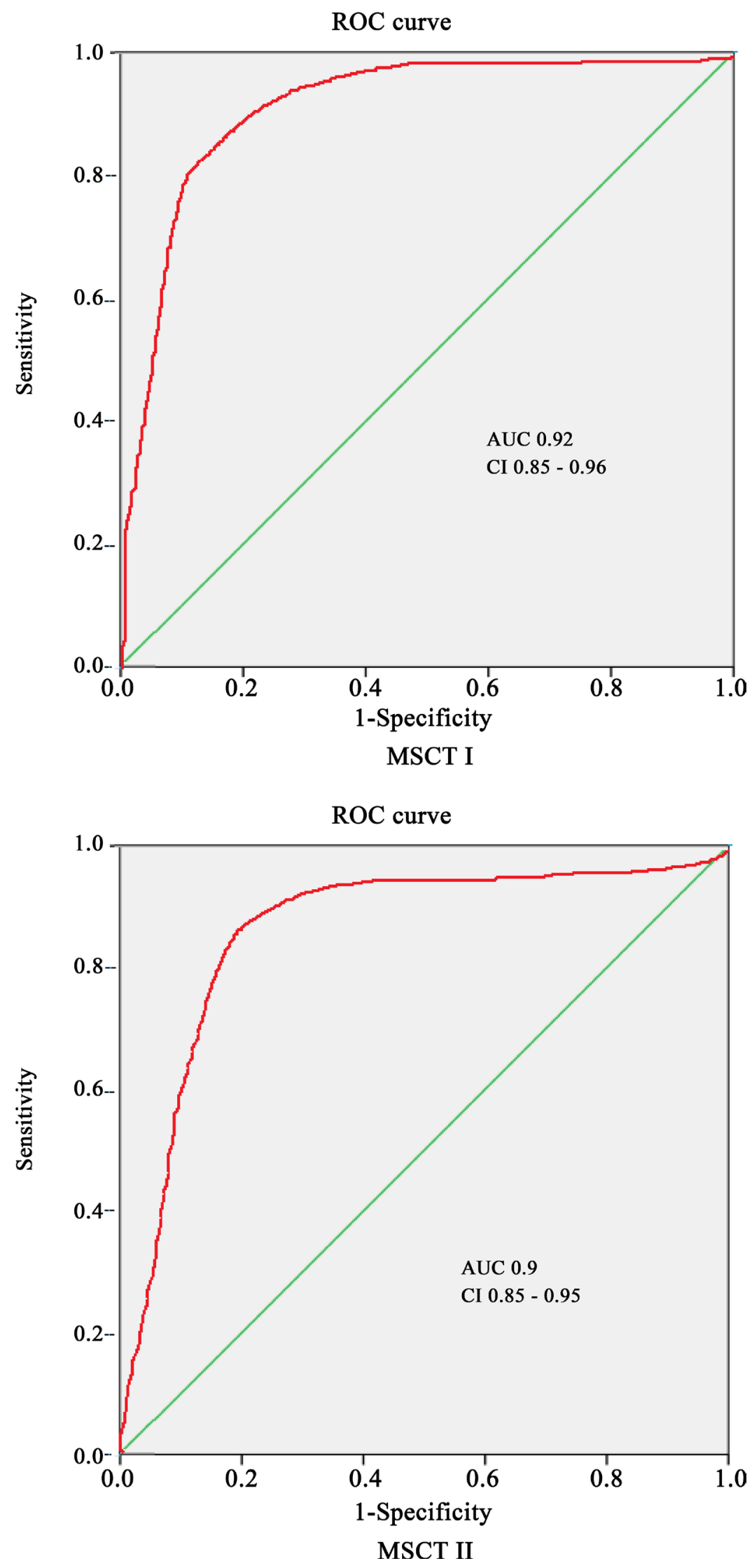

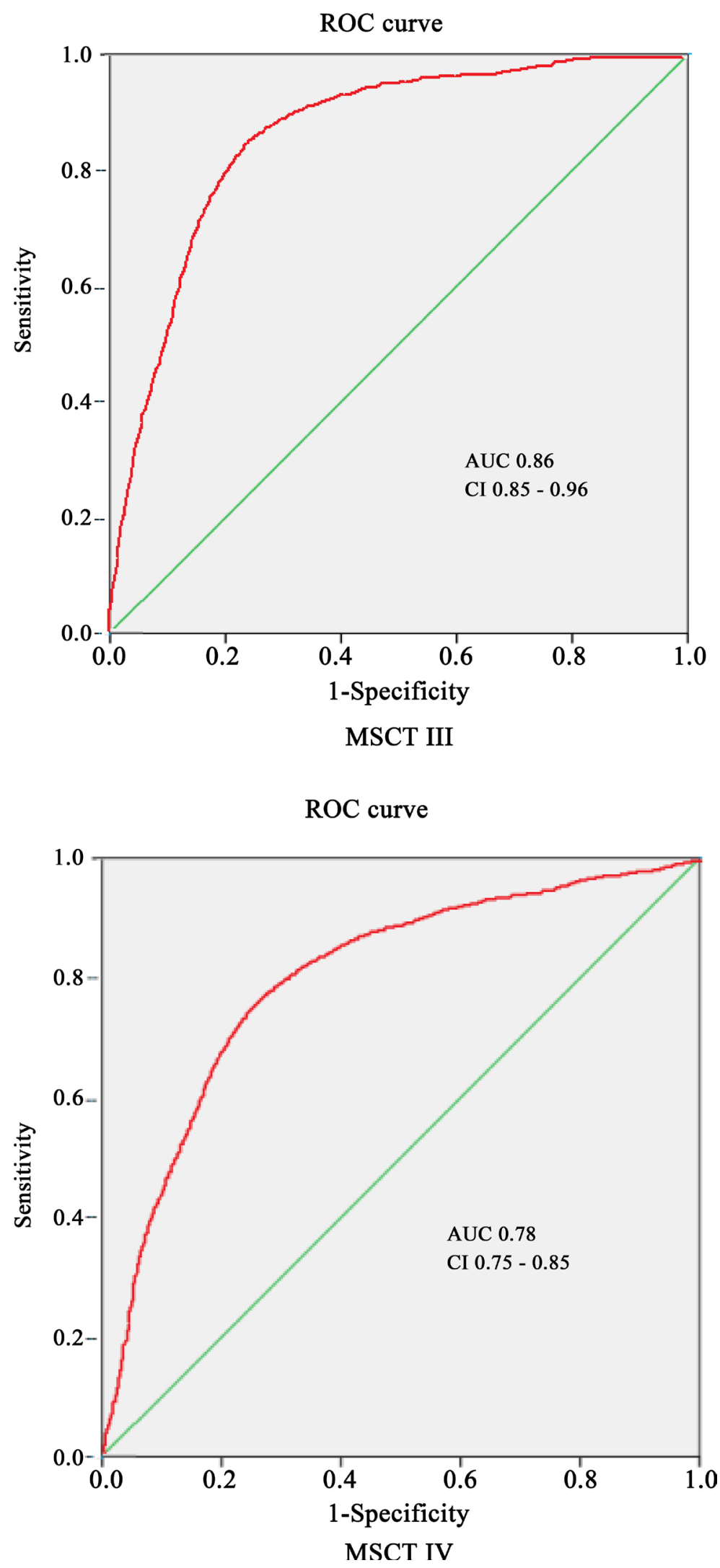

Figure 3. Sub-group risk stratification. 
Table 5. MSCT* scoring system vs. Mietteinen-lasota.

\begin{tabular}{lccccc}
\hline \multirow{2}{*}{ MSCT } & \multicolumn{5}{c}{ Miettinen-Lasota } \\
\cline { 2 - 5 } & Very low & Low & Moderate & High & Total \\
\hline Very low & 10 & 0 & 1 & 0 & 11 \\
Low & 1 & 8 & 0 & 0 & 9 \\
Moderate & 1 & 1 & 9 & 2 & 13 \\
High & 0 & 0 & 1 & 16 & 17 \\
Total & 12 & 9 & 11 & 18 & $\mathbf{5 0}$ \\
\hline
\end{tabular}

*MSCT: multislice computed tomography

mor rupture was recently considered in the modified NIH scheme and the prognostic heat maps [8]. All these tools are based on the evaluation of specimen's characteristics and are useful only for resected tumors.

It is admitted that the advent of tyrosine kinase inhibitor revolutionized the prognosis of metastatic and locally advanced tumor. Preoperative imatinib therapy can shrink the tumor size, increase the resectability rate and achieve a potentially better clinical outcome [9]-[12]. For these reasons the assessment of big lesions makes always a decisional controversy [13] [14].

Currently, borderline resectable tumors (big size, rupture risk, organs invasion), metastatic, and recurrent tumors are reasonable indications for neoadjuvant imatinib. However, there is no high-level evidence supporting this approach. National comprehensive cancer network (NCCN) recommends treating patients on an individual basis [15]. Preoperative assessment tool is needed for this category of patients.

Many radiologic signs were considered as predictor of malignant behavior and affecting survival rate for GISTs. Non gastric location, big size, irregular surface, unclear boundary, presence of invasion, heterogeneous enhancement, hepatic metastasis, and peritoneal dissemination were described in many series as associated with poor outcome [16]-[20]. These results should be confirmed for small tumors $<10 \mathrm{~cm}$. Statistics confusion is frequent for large tumors analysis. These lesions tend usually to have mucosal ulceration, central necrosis, cystic area, and heterogeneous enhancement following IV contrast injection. To our knowledge, MSCT risk stratification system was never described before. In our study we were able to validate a fifteen items score based on radiologic features which could significantly predict the outcome. It can be helpful in the management and guide MDT decision for locally advanced GISTs.

However, we consider these results as limited. The small size of the data, the retrospective review and the frequency of big lesions could make confusion. This preliminary validation of radiologic risk stratification is to be validated on larger prospective series.

\section{Conclusion}

Many sophisticated radiologic examinations are available in the investigation of GISTs. The role of MSCT in the diagnosis, staging, and follow up is non-discussable. Its role in the prognostic assessment should also be considered.

\section{References}

[1] Soreide, K., Sandvik, O.M., Soreide, J.A., Giljaca, V., Jureckova, A. and Bulusu, V.R. (2015) Global Epidemiology of Gastrointestinal Stromal Tumours (GIST): A Systematic Review of Population-Based Cohort Studies. Cancer Epidemiology, 40, 39-46. http://dx.doi.org/10.1016/j.canep.2015.10.031

[2] Lai, E.C., Lau S.H. and Lau, W.Y. (2012) Current Management of Gastrointestinal Stromal Tumors: A Comprehensive Review. International Journal of Surgery, 10, 334-340. http://dx.doi.org/10.1016/j.ijsu.2012.05.007

[3] Sharp, R.M., Ansel, H.J. and Keel, S.B. (2001) Best Cases from the AFIP: Gastrointestinal Stromal Tumor. Radio Graphics, 21, 1557-1560. http://dx.doi.org/10.1148/radiographics.21.6.g01nv231557

[4] Werewka-Maczuga, A., Osinski, T., Chrzan, R., Magda, B. and Andrzej, U. (2011) Characteristics of Computed Tomography Imaging of Gastrointestinal Stromal Tumor (GIST) and Related Diagnostic Problems. Polish Journal of Radiology, 76, 38-48.

[5] Ghanem, N., Altehoefer, C., Furtwängler, A., Winterer, J., Schäfer, O., Springer, O., Kotter, E. and Langer, M. (2003) Computed Tomography in Gastrointestinal Stromal Tumors. European Radiology, 13, 1669-1678. 
http://dx.doi.org/10.1007/s00330-002-1803-6

[6] Stiekema, J., Kol, S., Cats, A., van Coevorden, F. and van Sandick, J.W. (2012) The Outcome of Surgical Treatment of Gastrointestinal Stromal Tumors (GIST) of the Stomach in the Imatinib Era. European Journal of Surgical Oncology, 38, 771-772. http://dx.doi.org/10.1016/j.ejso.2012.06.120

[7] Lau, S., Tam, K.F., Kam, C.K., Lui, C.Y., Siu, C.W., Lam, H.S. and Mak, K.L. (2004) Imaging of Gastrointestinal Stromal Tumor (GIST). Clinical Radiology, 59, 487-498. http://dx.doi.org/10.1016/j.crad.2003.10.018

[8] Joensuu, H., Martin-Broto, J., Nishida, T., Richardt, P., Schoffski, P. and Maki, R.G. (2015) Follow-Up Strategies for Patients with Gastrointestinal Stromal Tumour Treated with or without Adjuvant Imatinib after Surgery. European Journal of Cancer, 51, 1611-1617. http://dx.doi.org/10.1016/j.ejca.2015.05.009

[9] Tirumani, S.H., Jagannathan, J.P., Krajewski, K.M., Shinagare, A.B., Jacene, H. and Ramaiya, N.H. (2013) Imatinib and beyond in Gastrointestinal Stromal Tumors: A Radiologist's Perspective. AJR American Journal of Roentgenology, 201, 801-810. http://dx.doi.org/10.2214/AJR.12.10003

[10] Shen, C., Chen, H., Yin, Y., Chen, J., Zhang, B., Chen, Z. and Chen, J. (2014) Preoperative Imatinib for Patients with Primary Unresectable or Metastatic/Recurrent Gastrointestinal Stromal Tumor. Clinics, 69, 758-762. http://dx.doi.org/10.6061/clinics/2014(11)09

[11] Shreyaskumar, P. (2012) Managing Progressive Disease in Patients with GIST: Factors to Consider besides Acquired Secondary Tyrosine Kinase Inhibitor Resistance. Cancer Treatment Reviews, 38, 467-472. http://dx.doi.org/10.1016/j.ctrv.2011.10.001

[12] Koontz, M.Z., Visser, B.M. and Kunz, P.L. (2012) Neoadjuvant Imatinib for Borderline Resectable GIST. Journal of the National Comprehensive Cancer Network, 10, 1477-1482.

[13] Kim, H.C., Lee, J.M., Kim, K.W., Park, S.H., Kim, S.H., Lee, J.Y., Han, J.K. and Choi, B.I. (2004) Gastrointestinal Stromal Tumors of the Stomach: CT Findings and Prediction of Malignancy. AJR American Journal of Roentgenology, 183, 893-898. http://dx.doi.org/10.2214/ajr.183.4.1830893

[14] Wilkinson, M.J., Fitzgerald, J.E., Strauss. D.C., Hayes, A.J., Thomas, J.M., Messiou, C., Fisher, C., Benson, C., Tekkis, P.P. and Judson, I. (2015) Surgical Treatment of Gastrointestinal Stromal Tumour of the Rectum in the Era of Imatinib. British Journal of Surgery, 102, 965-971. http://dx.doi.org/10.1002/bjs.9818

[15] Blay, J.Y., Bonvalot, S., Casali, P., Choi, H., Debiec-Richter, M., Dei Tos, A.P., et al. (2005) Consensus Meeting for the Management of Gastrointestinal Stromal Tumors. Report of the GIST Consensus Conference of 20-21 March 2004, under the Auspices of European Society for Medical Oncology. Annals of Oncology, 16, 566-578. http://dx.doi.org/10.1093/annonc/mdi127

[16] Yang, T.H., Hwang, J.I., Yang, M.S., Hung, S.W., Chan, S.W., Wang, J. and Tyan, Y.S. (2007) Gastrointestinal Stromal Tumors: Computed Tomographic Features and Prediction of Malignant Risk from Computed Tomographic Imaging. Journal of the Chinese Medical Association, 70, 367-373. http://dx.doi.org/10.1016/S1726-4901(08)70022-4

[17] Tateishi, U., Hasegawa, T., Satake, M. and Moriyama, N. (2003) Gastrointestinal Stromal Tumor: Correlation of Computed Tomography Findings with Tumor Grade and Mortality. Journal of Computer Assisted Tomography, 2, 792798. http://dx.doi.org/10.1097/00004728-200309000-00018

[18] Reece-Smith, A.M., Mac Goey, P., Shah, M.A., Leeder, P., Andrew, D.R., McCulloch, T. and Parsons, S.L. (2012) A Multi-Centre Analysis of the Impact of Updated Risk Stratification on Follow-Up of Gastric Gastro-Intestinal Stromal Tumors in the Post-Imatinibera. European Journal of Surgical Oncology, 38, 484-489. http://dx.doi.org/10.1016/j.ejso.2012.01.011

[19] Chun, H.J., Byun, J.Y., Chun, K.A., Rha, S.E., Jung, S.E., Lee, J.M., et al. (1998) Gastrointestinal Leiomyoma and Leiomyosarcoma: CT Differentiation. Journal of Computer Assisted Tomography, 22, 69-74. http://dx.doi.org/10.1097/00004728-199801000-00012

[20] He, Z.H., Lv, F.J., Cao, Z.F. and Qian, M.X. (2009) Value of Multi-Slice Spiral CT in Diagnosis of Malignant Gastrointestinal Stromal Tumors. The Chinese-German Journal of Clinical Oncology, 8, 443-446. http://dx.doi.org/10.1007/s10330-009-0102-y 